\title{
On Damage Detection System Information for Structural Systems
}

\author{
Thöns, Sebastian; Döhler, Michael; Long, Lijia
}

Published in:

Structural Engineering International

Link to article, DOI:

10.1080/10168664.2018.1459222

Publication date:

2018

Document Version

Peer reviewed version

Link back to DTU Orbit

Citation (APA):

Thöns, S., Döhler, M., \& Long, L. (2018). On Damage Detection System Information for Structural Systems. Structural Engineering International, 28(3), 255-268. https://doi.org/10.1080/10168664.2018.1459222

\section{General rights}

Copyright and moral rights for the publications made accessible in the public portal are retained by the authors and/or other copyright owners and it is a condition of accessing publications that users recognise and abide by the legal requirements associated with these rights.

- Users may download and print one copy of any publication from the public portal for the purpose of private study or research.

- You may not further distribute the material or use it for any profit-making activity or commercial gain

- You may freely distribute the URL identifying the publication in the public portal

If you believe that this document breaches copyright please contact us providing details, and we will remove access to the work immediately and investigate your claim 


\section{On Damage Detection System Information for Structural Systems}

Sebastian Thöns, Associate Professor, Technical University of Denmark, 2800 Lyngby, Denmark and BAM Federal Institute for Materials Research and Testing, Berlin, Germany

Michael Döhler, Research Scientist, Inria/IFSTTAR, Rennes, France

Lijia Long, PhD Student, BAM Federal Institute for Materials Research and Testing, Berlin, Germany

\section{ABSTRACT}

Damage detection systems (DDS) provide information of the structural system integrity in contrast to e.g. local information by inspections or non-destructive testing techniques. In this paper, an approach is developed and demonstrated to utilize DDS information to update the structural system reliability and to integrate this information in structural system risk and utility analyses. For this aim, a novel performance modelling of DDS building upon their system characteristics and non-destructive testing reliability is introduced. The DDS performance modelling accounts for a measurement system in combination with a damage detection algorithm attached to a structural system in the reference and damage states and is modelled with the probability of indication accounting for type I and II errors. In this way, the basis for DDS performance comparison and assessment is provided accounting for the dependencies between the damage states in a structure. For updating of the structural system reliability, an approach is developed based on Bayesian updating facilitating the use of DDS information on structural system level and thus for a structural system risk analysis. The structural system risk analysis encompasses the static, dynamic, deterioration, reliability and consequence models, which provide the basis for the system model for calculating the direct risks due to component failure and the indirect risks due to system failure. Two case studies with the developed approach demonstrate a high Value of DDS Information due to risk and expected cost reduction.

KEYWORDS: Damage detection, Value of Information, Structural systems, Damage detection uncertainty modelling

\section{INTRODUCTION}

Damage detection systems (DDS) provide information about the integrity and the performance of a structural system. The performance of a structural system is characterized by its safety, i.e. the system reliability and risks, and its functionality, i.e. the associated expected benefits and costs. The structural system reliability is modelled with failure and damage mechanisms based on the static and dynamical system behaviour. The failure and damage mechanisms have generally a statistical dependence caused by common influencing factors, such as environmental conditions, production and construction processes and material characteristics [21, 49, 52].

Damage detection information is characterized by providing an indication of damage of a structural system subjected to a finite precision [16]. The damage detection information provided by a measurement system and a damage detection algorithm (DDA) refers to a change in the structural system characteristics in relation to a 
reference state of the structural system [15,7]. Damage detection information thus account for the dependencies in the entire structural system.

Both, structural system performance modelling and damage detection algorithms, have progressed significantly but separately in the scientific literature during the last decades, see e.g. $[9,14,37]$ and $[4,13,15$, 17]. However, it has been demonstrated that structural system identification based on response measurements can be combined with updating of the structural reliability and that such information contribute to the accuracy of the structural condition and thus to the structural safety, see e.g. [48].

In this paper we focus thus (1) on explicitly modelling the system characteristics for the structural system and the DDS system including their costs, consequences and functionalities (Section 2), (2) on utilising DDS for updating the structural system reliability (Section 3) and (3) on identifying conditions under which DDS information may have a high value by utilising the Bayesian decision analysis (Section 4). The developed approaches are elaborated with two case studies, namely (1) an example focussing on how the structural system reliability can be updated and how a risk reduction can be achieved (Section 3.4) and (2) a case study containing a Value of DDS Information analysis of a bridge girder under high degradation (Section 5). The paper closes with conclusions in Section 6.

\section{STRUCTURAL PERFORMANCE MODELLING, INSPECTION AND DAMAGE DETECTION PERFORMANCE MODELLING}

In this section, the characteristics of the structural performance modelling and damage detection monitoring are outlined.

\subsection{Structural system performance and risks modelling}

The performance of a structural system is characterized by its safety, i.e. the system reliability and risks, and its functionality, i.e. the associated expected benefits and costs. The structural system reliability and risk are described by means of the structural system theory. It takes basis in the probabilistic mechanical behaviour of the system in conjunction with its loading, resistance and deterioration models and the quantification of the system risks and utilities in conjunction with a consequence model.

Structural failure can be caused by static or dynamic extreme loading of the system and/or its components. An extreme structural system loading implies a high statistical dependence of the component loadings. The dependence in the resistance is governed by the production (e.g. section properties and material parameters) and the construction process (e.g. imperfections) of the structure (see e.g. [21]). Deterioration may cause damages to the structural system and can affect the entire structural system or can occur at different locations and in different time periods, depending on the material and the nature of the damage mechanism. The spatial and componential dependence of a damage mechanism can thus vary significantly (as e.g. for fatigue of steel structures, see e.g. [26]). Failures of the structural system and its components caused by damage mechanisms 
rely thus on the structural system characteristics and the loading, resistance and damage mechanisms dependencies [37].

The performance of a structural system both in regard to system failure and system damage can be described with logical systems, Daniels Systems, Bayesian networks (e.g. [19], [9] and [29]). In general, the probability $P\left(F_{S}\right)$ of a structural system failure is calculated by integrating the joint probability density over the space of system failure $\Omega_{F_{S}}$,

$P\left(F_{S}\right)=\int_{\Omega_{F_{S}}} f_{F_{S}}(\mathbf{X}) d \mathbf{X}$

where the system failure space $\Omega_{F_{S}}$ may be e.g. defined with limit state functions.

The structural risks can then be calculated with the component and system probability of failure $\left(P\left(F_{i}\right)\right.$ and $P\left(F_{S}\right)$ ) and the consequences of component and system failure $\left(C_{\mathrm{c}}\right.$ and $\left.C_{S}\right)$. The risk may be classified into direct risk due to component failure and indirect risks due to system failure ( $R_{D}$ and $R_{I D}$ ) tasking basis in [2]:

$R=R_{D}+R_{I D}=\sum_{i=1}^{n_{c}} P\left(F_{i}\right) \cdot C_{\mathrm{c}}+P\left(F_{S}\right) \cdot C_{S}$

\subsection{Damage detection}

Automatic damage detection methods in a structural health monitoring (SHM) context are based on the chosen measurement technology for the desired monitoring aim [16], [17]. To illustrate the integration of damage detection information into the performance analysis of a structure, a vibration-based damage detection method is considered in the following.

Vibration monitoring is one of the most known and developed techniques for long term SHM and has been recognized as an addition or alternative to visual inspections or local non-destructive testing performed manually, see [15], [16], [25], [12]. The rationale is that damages have an effect on the structural stiffness, and thus on the modal parameters (modal frequencies, damping ratios and mode shapes) which characterize the dynamics of the structure. A network of vibration sensors (usually accelerometers) is attached to the structure, measuring continuously the structural vibration response to ambient excitation like wind, traffic, waves or other sources. Changes in the measured signals with respect to the dynamic characteristics of the structure then indicate damage. Since changes in the environmental conditions (like temperature changes) also lead to changes in the signals, they must be taken care of (e.g. [3], [8]).

Methods for vibration-based damage detection compare measurement data from a (healthy) reference state of the structure with data from the current, potentially damaged state. An alarm is raised if a distance measure between both states exceeds a threshold. There are many methods for damage detection in this context [7]. For example, a straightforward approach is to identify the modal parameters from measurements of both the reference and current states, and to compare them directly [25]. Other methods confront current measurements 
to a reference in a statistical distance measure, without modal parameter identification. For instance, such methods include non-parametric change detection based on novelty detection [43], Kalman filter innovations [6], methods from machine learning [16] and many more. Belonging also to this class of methods, the statistical subspace-based damage detection methods (see [4], [5], [11], [12], [13]) offer a flexible and theoretically well founded framework that we use in this paper.

In the following, the subspace-based damage detection algorithm is introduced as an example of global automated damage detection methods. With this method, vibration measurements from the current system are compared to a reference state in a subspace-based residual vector. In a hypothesis test, the uncertainties of the residual are taken into account and the respective $\chi^{2}$ test statistic is compared to a threshold in order to decide if the structure is damaged or not. Based on these properties, the $\chi^{2}$ test statistic is considered as the damage indicator value (DIV) for damage monitoring.

\subsubsection{Dynamic structural system model}

The behaviour of the monitored structure is assumed to be described by a linear time-invariant dynamical system

$$
\mathbf{M} \ddot{z}(t)+\mathbf{C} \dot{z}(t)+\mathbf{K} z(t)=v_{F}(t)
$$

where $t$ denotes continuous time, $\mathbf{M}, \mathbf{C}$ and $\mathbf{K} \in \mathbb{R}^{m \times m}$ are the mass, damping and stiffness matrices, vector $z \in \mathbb{R}^{m}$ collects the displacements of the $m$ degrees of freedom of the structure, and $v_{F}(t)$ is the external force which is usually unmeasured for long-term monitoring. Observing the structural system (3) with a set of $r$ acceleration sensors yields the measurements

$y(t)=L \ddot{z}(t)+e(t)$

where $y \in \mathbb{R}^{r}$ is the measurement vector, matrix $L \in \mathbb{R}^{r \times m}$ indicates the sensor locations and $e$ is the measurement noise.

Measurements are taken at discrete time instants $t=k \tau$, where $k$ is an integer and $\tau$ the time step. Sampling model (3)-(4) at rate $1 / \tau$ and transforming it to a first order system yields the discrete-time state space model

$$
\begin{aligned}
x_{k+1} & =A x_{k}+v_{k} \\
y_{k} & =C x_{k}+w_{k}
\end{aligned}
$$

where the states, outputs, state transition matrix and output matrix are

$$
x_{k}=\left[\begin{array}{c}
z(k \tau) \\
\dot{z}(k \tau)
\end{array}\right], y_{k}=y(k \tau), A=\exp \left(\left[\begin{array}{cc}
0 & I \\
-\mathbf{M}^{-1} \mathbf{K} & -\mathbf{M}^{-1} \mathbf{C}
\end{array}\right] \tau\right), C=L\left[-\mathbf{M}^{-1} \mathbf{K} \quad-\mathbf{M}^{-1} \mathbf{C}\right],
$$

respectively, and the appropriate state noise and output noise terms are $v_{k}$ and $w_{k}$. The state noise is related to the unmeasured external force $v_{F}$, and the output noise depends both on $v_{F}$ and the measurement noise $e$. Both noise terms are assumed to be stationary white noise for the theoretical outline of the damage detection method. While this assumption seems to be restrictive in real applications on civil structures where the ambient 
excitation may rather be modelled by non-stationary and coloured noise, some robustness of the damage detection method to these conditions has been shown [4], which is supported by several case studies on structures in operation, e.g. [12]. The theoretical system order of system (5) is the dimension of the states, $n=$ $2 \mathrm{~m}$. Note that the above modelling is not only valid for acceleration measurements as in (4), but generalizable to displacement and velocity measurements.

The modal parameters of the model in Equ. (3)-(4), i.e. the natural frequencies, damping ratios and observed mode shapes, are equivalently found in the system matrices $(A, C)$ of model (5). Damages in the monitored system correspond to changes in the matrices $\mathbf{M}, \mathbf{C}$ and $\mathbf{K}$ in Equ. (3), e.g. loss of mass or loss of stiffness, and affect thus the system matrices $(A, C)$ and the modal parameters. Hence, damages in model (3) can be equivalently detected as changes in the modal properties related to system matrices $(A, C)$ in Equ. (5).

Based on measurements $y_{k}$ of the monitored system from a reference and from a possibly damaged state, a residual vector is defined based on subspace properties without identifying the system matrices $(A, C)$, as outlined in the following sections.

\subsubsection{Subspace properties}

From measurement data $\left\{y_{k}\right\}_{k=1, \ldots, N}$, the correlations $R_{i}=\frac{1}{N} \sum_{k=1}^{N} y_{k} y_{k-i}^{T}$ are computed for $i=1, \ldots, p+q$, where $p$ and $q$ are chosen parameters (usually $p+1=q$ ) with $\min (p r, q r) \geq n$ [11]. Then, they are filled into block Hankel matrix

$\mathcal{H}=\left(\begin{array}{cccc}R_{1} & R_{2} & \ldots & R_{q} \\ R_{2} & R_{3} & \ldots & R_{q+1} \\ \vdots & \vdots & \ddots & \vdots \\ R_{p+1} & R_{p+2} & \cdots & R_{p+q}\end{array}\right)$,

which possesses the factorization property $\mathcal{H}=\mathcal{O C}$ into observability matrix

$\mathcal{O}=\left[\begin{array}{c}C \\ C A \\ \vdots \\ C A^{p+1}\end{array}\right]$

and controllability matrix $\mathcal{C}$. Matrix $\mathcal{O}$ can be obtained from a singular value decomposition (SVD) of $\mathcal{H}$, truncated at the model order $n$, as

$\mathcal{H}=U \Delta V^{T}=\left(\begin{array}{ll}U_{1} & U_{0}\end{array}\right)\left(\begin{array}{ll}\Delta_{1} & \\ & \Delta_{0}\end{array}\right) V^{T}, \mathcal{O}=U_{1} \Delta_{1}^{1 / 2}$.

Note that the truncated singular values correspond to noise and are usually small, i.e. $\Delta_{0} \approx 0$.

Once $\mathcal{O}$ is obtained from Equ. (7) and (9), the system matrices $(A, C)$ can be extracted from Equ. (8) for subspace-based system identification (see [30], [10]), from which the modal parameters could be obtained. 
Instead of doing this system identification step, however, the subspace properties are used for the definition of a damage detection residual and a subsequent damage detection test.

\subsubsection{Damage detection residual and test}

Let $\mathcal{H}^{0}$ be a Hankel matrix (Equ. (7)) filled with data from a (healthy) reference state, and let its SVD in Equ. (9) be given. Define its left null space matrix $S$, obtained as $S=U_{0}$ in Equ. (9), such that $S^{T} \mathcal{H}^{0} \approx 0$.

Now, let new measurements $\left\{y_{k}\right\}_{k=1, \ldots, N}$ from an unknown state of the system be given, from which a new Hankel matrix $\mathcal{H}$ is computed. If the data comes from the system in the reference state, $S$ is still a null space of $\mathcal{H}$ since the modal parameters and thus matrices $(A, C)$ (up to a change of basis) are unchanged. Thus, $S^{T} \mathcal{H} \approx 0$ is a characteristic property of the system in the reference state.

However, if the system is damaged, the modal properties related to matrices $(A, C)$ and thus $\mathcal{O}$ in Equ. (8) change, and the mean of the product $S^{T} \mathcal{H}$ deviates from 0 . Note that matrix $\mathcal{H}$ is computed from data and does not depend on the state basis of matrices $(A, C)$. These properties lead to the definition of the residual vector (see [4], [5], [13])

$$
\zeta=\sqrt{N} \operatorname{vec}\left(S^{T} \mathcal{H}\right)
$$

where $N$ is the number of samples on which $\mathcal{H}$ is computed. This residual vector is asymptotically Gaussian (for large $N$ ) with zero mean in the reference state and non-zero mean in the damaged state [4]. Thus, a change in the system corresponds to a deviation from 0 in the mean value of the residual vector. The corresponding hypothesis test (for a decision between $\mathbf{H}_{0}$ : the system is in the reference state, and $\mathbf{H}_{1}$ : the system is in a damaged state) leads to the test statistic

$$
d=\zeta^{T} \Sigma^{-1} \zeta
$$

where $\Sigma=\mathbf{E}\left(\zeta \zeta^{T}\right)$ is the residual covariance matrix. An estimate of $\Sigma$ is the sample covariance that is computed on several realizations of the residual using measurement data in the reference state. Due to the distribution properties of the residual, the test statistic (11) is asymptotically $\chi^{2}$ distributed with a noncentrality parameter in the damaged state [4] [13]. To decide if the monitored structure is damaged or not, the test statistic is compared to a threshold. Based on realizations of the test statistic in the reference state, the threshold is typically chosen so that the probability of false alarms (type I error) is below some chosen level, while keeping in mind that a lower probability of false alarms (lower type I error) also leads to a lower probability of indication (higher type II error) for small damages. In practice, a trade-off between both needs to be made. In the following, the event of indication is defined as a detection of damage, i.e. when the test statistic exceeds the threshold. Note that the terms probability of indication (PoI) and probability of detection (PoD) can be used equivalently. Thanks to the previous properties, the test statistic (11) is considered as the DIV in the following analysis. 
Note that Equ. (11) is the non-parametric version of the damage detection test [3] [13]. A detailed description of the statistical framework and more theoretical and computational insight of this method is given in [4] [11] [13].

\section{UPDATING THE STRUCTRAL SYSTEM RELIABILITY WITH DAMAGE DETECTION INFORMATION}

The approach to update the structural system reliability and risks is developed in Section 3.3 based on an outline of the inspection and measurement performance modelling (Section 3.1) and the DDS performance modelling (Section 3.2).

\subsection{Inspection and measurement performance modelling}

The inspection and measurement performance can be modelled based on the approaches of non-destructive testing/evaluation/inspection (NDT, NDI or NDE) reliability modelling, see e.g. [44], [34], [18]. In the following the methods of NDT modelling are reviewed and a consistent NDT performance modelling is introduced providing the basis for the DDS performance assessment.

The NDT reliability calculation is based upon modelling or measuring the signal given a damage and the noise (given no damage) of the NDT hardware. Assume that an indication event $I$ is defined when the signal exceeds a pre-defined threshold $t_{D}$. Depending of this threshold, the conditional probabilities of the indication event are calculated with the signal $s$ and the noise $s_{0}$, where $n_{D}$ component damage states of a structural component are modelled as discrete and disjoint, i.e. $\psi_{j}, j=1, \ldots, n_{D}$, and $\psi_{0}$ is defined as the undamaged state. The probability of the complementary events indication $(I)$ and no-indication $(\bar{I})$ for a component damage state $\psi_{j}$, namely $P\left(I \mid \psi_{j}\right)$ and $P\left(\bar{I} \mid \psi_{j}\right)$ respectively, are determined by integrating the probability density $f$ of the signal,

$$
\begin{aligned}
& P\left(\bar{I} \mid \psi_{j}\right)=\int_{-\infty}^{t_{D}} f\left(s \mid \psi_{j}\right) \mathrm{d} s, \\
& P\left(I \mid \psi_{j}\right)=\int_{t_{D}}^{\infty} f\left(s \mid \psi_{j}\right) \mathrm{d} s .
\end{aligned}
$$

The probability of indication and no-indication given no damage $\left(P\left(I \mid \psi_{0}\right)\right.$ and $\left.P\left(\bar{I} \mid \psi_{0}\right)\right)$ are calculated by integrating the noise $s_{0}$,

$$
P\left(\bar{I} \mid \psi_{0}\right)=\int_{-\infty}^{t_{D}} f\left(s_{0} \mid \psi_{0}\right) \mathrm{d} s_{0},
$$


$P\left(I \mid \psi_{0}\right)=\int_{t_{D}}^{\infty} f\left(s_{0} \mid \psi_{0}\right) \mathrm{d} s_{0}$.

Note that these probabilities are given for an upper boundary threshold $t_{D}$, i.e. damage is indicated when the signal exceeds this threshold, but they can be easily generalized to the case of, e.g., lower boundary or twosided thresholds. The probability densities $f$ of the noise and the signal can be determined with inter-laboratory tests performed independently several times (so called round robin tests) which imply a frequentistic basis (as e.g. summarized in [44], [34], [18]) or analytically and numerically by simulating the NDT process (see e.g. [42], [33]).

With Equ. (12) to (15), the probability of indication (PoI), the probability of false alarm (PFA) and the receiver operating characteristics (ROC) are defined. An example of a PoI (or probability of detection, PoD) plot covering the probability of indication given no damage, $\psi_{0}$, and different damage states, $\psi_{j}, j=1, \ldots, n_{D}$, is depicted in Figure 1 for a constant threshold. Please note that the diagram contains a (non-zero) probability of indication given no damage $\left(\psi_{0}\right)$ which is also referred to as the probability of false alarm.

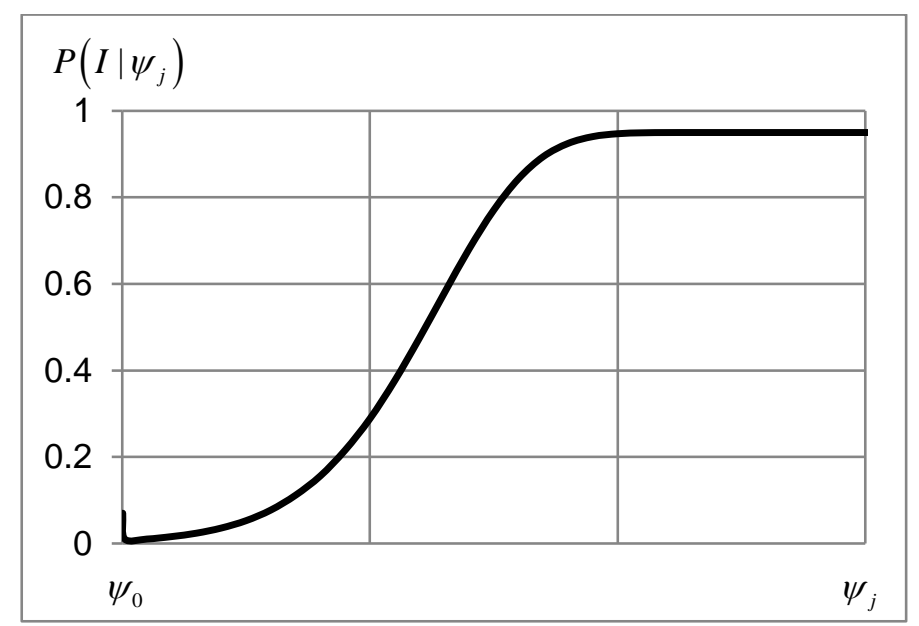

Figure 1: Exemplary probability of indication curve for one component

The PFA is defined as the probability of indication given an undamaged structural component $P\left(I \mid \psi_{0}\right)$, see e.g. [22]. It is understood that the PFA is caused by noise, since damage is absent by definition. Data normalizing efforts usually aim at reducing or averaging out the noise [17]. The ROC is a plot of the PoI, $P\left(I \mid \psi_{i}\right)$, against the PFA, $P\left(I \mid \psi_{0}\right)$, for a particular damage state $\psi_{i}$ but varying threshold $t_{D}$.

The approach of NDT reliability modelling as outlined above has recently been applied on a component level to model the PoI of damage detection algorithms (DDA), for example with the purpose of assessing their quality, see e.g. [22], [38], [40]. For this aim the signal is defined as the DIV in a damaged state and the noise is defined as the DIV produced by the damage detection algorithm in the reference state, i.e. the state where the structural system is undamaged. With these definitions, the probabilities of indication and no-indication given no damage and damage can be calculated (see Equ. (12) to (15)). 


\subsection{Damage detection system performance modelling}

In order to apply the above NDT reliability modelling to DDS, important characteristics of the DDS information have to be taken into account, namely,

(a) DDS information are provided by algorithms processing measurement system signals, and

(b) the measurement system is attached to a structural system, and

(c) the DDS is operated by humans.

In particular, regarding (a), the DIV is usually a random variable due to statistical signal processing of finite measurement data. Amongst others, its statistical properties are influenced by measurement uncertainties, uncertain environmental conditions like properties of the ambient excitation and data length. Regarding (b), the DIV for damage detection is a value that indicates changes of the entire structural system. Damages in each of the components can thus have a different influence on the DIV. Hence, the damage states of the system need to be defined in conjunction with the structural components and the structural system performance. DDS information are subjected to human errors (c), which need to be considered [42].

These two major DDS characteristics are incorporated as follows. The structural system is discretized into $n_{c}$ components with discrete damage states. For example, these components may correspond to the elements of a finite element model of the structure. Let each of the components $i \in\left\{1, \ldots, n_{c}\right\}$ have $\left(n_{D}+1\right)$ possible states, namely an undamaged state and $n_{D}$ damaged states. For simplicity of notation, an equal number of $n_{D}$ damaged states is assumed for each component, which can be easily generalized. The respective states are denoted by $\psi_{i, j_{i}}$, where $j_{i}=0$ for the undamaged state and $j_{i}=1, \ldots, n_{D}$ for the damaged states of component $i$. Then, a full discretization of the structural system states contains the possible combinations of all these states, amounting to $\left(n_{D}+1\right)^{n_{c}}-1$ system damage states plus the undamaged state. Each of these states corresponds then to a particular set of matrices describing the monitored system in (3), where the damage states correspond to modifications of the matrices $\mathbf{M}, \mathbf{C}$ and $\mathbf{K}$. The system damage space $\boldsymbol{\Psi}^{n_{c}}$ is then defined by the vectors $\boldsymbol{\psi}_{\mathbf{j}}=\left\{\psi_{1, j_{1}}, \ldots, \psi_{n_{c}, j_{n_{c}}}\right\}$, where $\mathbf{j}=\left\{j_{1}, \ldots, j_{n_{c}}\right\}$. Note that $\boldsymbol{\psi}_{0}=\left\{\psi_{1,0}, \ldots, \psi_{n_{c}, 0}\right\}$ denotes the undamaged state.

Let the DIV $d_{\mathrm{j}}$ be given, which is obtained for any of these states $\boldsymbol{\psi}_{\mathrm{j}}$, whether undamaged or damaged, and let its probability density function be given by $f\left(d_{\mathbf{j}} \mid \boldsymbol{\psi}_{\mathbf{j}}\right)$. The probabilities of indication and of no-indication given a damaged structural system can then be calculated by integrating the probability densities of the DIV, namely

$$
\begin{aligned}
& P\left(\bar{I}_{S} \mid \boldsymbol{\psi}_{\mathbf{j}}\right)=\int_{-\infty}^{t_{S, D}} f\left(d_{\mathbf{j}} \mid \boldsymbol{\psi}_{\mathbf{j}}\right) \mathrm{d} d_{\mathbf{j}}, \\
& P\left(I_{S} \mid \boldsymbol{\psi}_{\mathbf{j}}\right)=\int_{t_{S, D}}^{\infty} f\left(d_{\mathbf{j}} \mid \boldsymbol{\psi}_{\mathbf{j}}\right) \mathrm{d} d_{\mathbf{j}} .
\end{aligned}
$$


Note that the probability of no-indication in (16) is the type II error. In the considered damage detection method, the DIV is $\chi^{2}$ distributed (Equ. (11)). Thus, the probability density function $f$ corresponds to the classical $\chi^{2}$ distribution in the undamaged state, and to the non-central $\chi^{2}$ distribution in the damaged state, respectively. An example of the distributions of DIVs $d_{0}$ and $d_{\mathbf{j}}$ with $\mathbf{j} \neq 0$ are given in Figure 2 . The threshold, which is set up from test values in the reference state for a given type I error, the type II error (corresponding to (16)) and the probability of indication (corresponding to (17)) are depicted.

The distribution of the DIV that is required to evaluate the probabilities in Equ. (16) and (17) may be obtained in two different ways. First, it can be derived from the theoretical properties of the DDA, the damage state and (assumptions on the) statistical properties of the measurement data. For the presented damage detection method, the distribution of the DIV is known depending on a damage parameterization (see details e.g. in [4,47]). In this case, the damage parameters can be obtained from a finite element model of the structure. Second, the distribution of the DIV may be obtained numerically from Monte Carlo simulations, where measurement data is simulated in the respective damage states. This second option is particularly useful when the theoretical DIV distribution is unknown or difficult to evaluate, however, it comes with an additional computational burden.

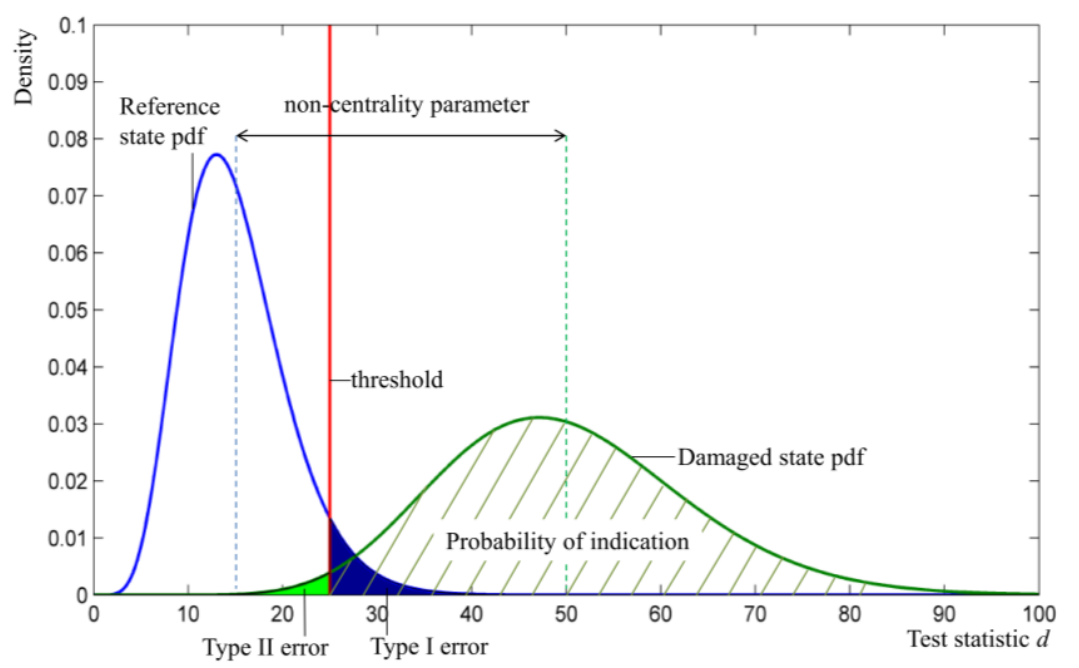

Figure 2: Scheme of probability density functions (pdf) of damage detection test statistic $d$ in the reference and in a damaged state.

An example of the probability of indication computed with Equ. (17) is depicted in Figure 3 for a system with two components, building upon the subspace-based DDA (Section 2.2). It is observed that the probability of indication of a damage state $P\left(I_{S} \mid\left\{\psi_{1, j_{1}}, \psi_{2, j_{2}}\right\}\right)$ with $\left\{j_{1} \neq 0, j_{2} \neq 0\right\}$ is higher than for component damage states $\left(P\left(I_{S} \mid\left\{\psi_{1, j_{1}}, \psi_{2, j_{2}}\right\}\right)\right.$ with $\left\{j_{1}=0, j_{2} \neq 0\right\}$ or $\left.\left\{j_{1} \neq 0, j_{2}=0\right\}\right)$. 


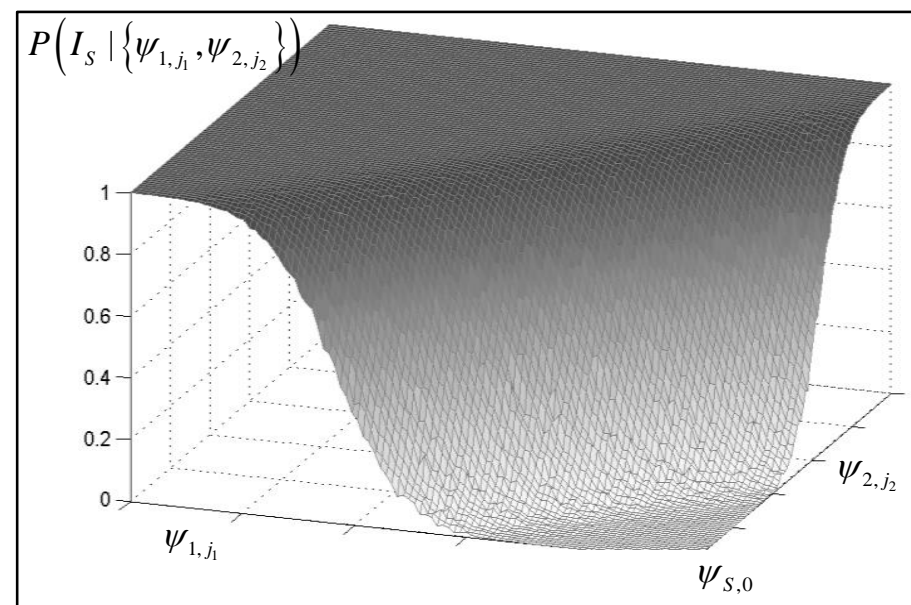

Figure 3: Example of a probability of indication curve for a system consisting of two components in dependency of the component damage state $\psi_{1, j_{1}=1} \ldots \psi_{1, j_{1}=n_{D}}$ and $\psi_{2, j_{2}=1} \ldots \psi_{2, j_{2}=n_{D}}$ and $\psi_{S, 0}=\left\{\psi_{1,0}, \psi_{2,0}\right\}$

Note that the determination of the probability of indication for a structural system accounting for all possible damages states may be a non-trivial task as the number of the damage states increases exponentially with an increasing number of components. One approach to circumvent this challenge is to infer the probability of indication by the properties of the damage detection algorithm [47].

\subsection{Structural system performance updating}

The approaches of structural reliability updating underwent several developments in the last decades. An early and comprehensive work by [24] contains a framework for updating of the structural reliability including inspection and monitoring information and accounting for their measurement uncertainty. Recently, approaches emerged for modelling and updating the system deterioration state of structures, taking into account the aspect of spatial correlation among element deterioration [14] [1] [27] [36] [31]. However, the impact of deterioration on the structural system reliability is seldom included in these works and only very recent studies can be found integrating the deterioration and the structural system reliability [23] [32] [41]. The outlined approaches have in common that only local information provided by e.g. inspections is utilised, i.e. these approaches do not cover the characteristics of damage detection system (DDS) information, namely the dependency of the measurement system and structural system and that DDS may be able to detect correlated component damage states with a higher probability.

The formulation of the structural performance and the DDS performance on system level (Section 3.2) facilitates an updating of the structural system reliability. The probability of structural system failure subjected to the system damage $\boldsymbol{\Psi}^{n_{c}}\left(t_{S}\right)$ given the DDS information of no-indication, $P\left(F_{S}\left(t_{S}\right)\left|\boldsymbol{\Psi}^{n_{c}}\left(t_{S}\right)\right| \bar{I}_{S}\right)$, can be determined utilizing Bayesian updating for any point in time during the service life $t_{s}$ with 


$$
\begin{aligned}
P\left(F_{S}\left(t_{S}\right)\left|\boldsymbol{\Psi}^{n_{c}}\left(t_{S}\right)\right| \bar{I}_{S}\right) & =\frac{P\left(\bar{I}_{S}\left|F_{S}\left(t_{S}\right)\right| \boldsymbol{\Psi}^{n_{c}}\left(t_{S}\right)\right) P\left(F_{S}\left(t_{S}\right) \mid \boldsymbol{\Psi}^{n_{c}}\left(t_{S}\right)\right)}{P\left(\bar{I}_{S} \mid \boldsymbol{\Psi}^{n_{c}}\left(t_{S}\right)\right)} \\
& =\frac{P\left(F_{S}\left(t_{S}\right)\left|\boldsymbol{\Psi}^{n_{c}}\left(t_{S}\right) \cap \bar{I}_{S}\right| \boldsymbol{\Psi}^{n_{c}}\left(t_{S}\right)\right)}{P\left(\bar{I}_{S} \mid \boldsymbol{\Psi}^{n_{c}}\left(t_{S}\right)\right)} .
\end{aligned}
$$

It should be noted that DDS information itself refers to a point or period in time, which however, is neglected here for clarity.

The probability of no-indication $P\left(\bar{I}_{S} \mid \Psi^{n_{c}}\left(t_{S}\right)\right)$ given the system damage state can be calculated based on the developed approach for the DDS performance calculation (Equ. (17)). Following [20], the marginal probability of no-indication is calculated by integrating the product of the conditional probability of noindication $\left(1-P\left(I_{S} \mid \boldsymbol{\Psi}^{n_{c}}\right)\right)$ and the joint probability density of the system damage space $f_{\Psi^{n_{c}}}\left(\boldsymbol{\Psi}^{n_{c}}\right)$ over the damage state spaces. The integration is performed over the space $\Omega_{\bar{I}_{S}}$ which is defined with the limit state function $g_{\bar{I}_{S}}$ as the difference between the probability of indication $P\left(I_{S} \mid \Psi^{n_{c}}\right)$ and a uniformly distributed random variable $u$, holding

$$
P\left(\bar{I}_{S}\right)=\int_{\Omega_{\bar{I}_{S}}}\left(1-P\left(I_{S} \mid \boldsymbol{\Psi}^{n_{c}}\right)\right) f_{\Psi^{n_{c}}}\left(\boldsymbol{\Psi}^{n_{c}}\right) \mathrm{d} \boldsymbol{\Psi}^{n_{c}} \text { with } \Omega_{\bar{I}_{S}}=\left\{g_{\bar{I}_{S}}=P\left(I_{S} \mid \boldsymbol{\Psi}^{n_{c}}\right)-u\right\} .
$$

To illustrate the characteristics of DDS information, the risk quantification model is further detailed accounting for the direct and indirect risks ( $R^{D D S}$ and $R_{I D}^{D D S}$ ) at time $t_{S}$ with DDS information and yielding

$$
R^{D D S}\left(t_{S}\right)=R_{D}\left(t_{S}\right)+R_{I D}^{D D S}\left(t_{S}\right)=\sum_{i=1}^{n_{c}} P\left(F_{i}\left(t_{S}\right)\right) \cdot C_{\mathrm{c}}+P\left(F_{S}\left(t_{S}\right) \mid \bar{I}_{S}\left(t_{S}\right)\right) \cdot C_{S} \cdot
$$

Only the indirect risks are updated due to the system characteristics of the DDS information. In contrast, the direct risks are updated by non-destructive testing (NDT) information as these refer to local damages. It may be argued that DDS information may apply to both the structural system and its components. However, the updating of the component performance presupposes a damage localisation, which is outside the scope of this paper.

A risk reduction $\Delta R\left(t_{S}\right)$ can be quantified by subtracting the risk given DDS information and accounting for the expected SHM costs $E\left[C_{D D S}\left(t_{S}\right)\right]$ from the total risk without DDS information leading to

$$
\Delta R\left(t_{S}\right)=R\left(t_{S}\right)-\left(R^{D D S}\left(t_{S}\right)+E\left[C_{D D S}\left(t_{S}\right)\right]\right)
$$

A relative risk reduction relates the risk reduction to the total risks not utilizing DDS information with

$$
\frac{\Delta R\left(t_{S}\right)}{R\left(t_{S}\right)}=\frac{R\left(t_{S}\right)-\left(R^{D D S}\left(t_{S}\right)+E\left[C_{D D S}\left(t_{S}\right)\right]\right)}{R\left(t_{S}\right)} .
$$




\subsection{Example: structural risk reduction with DDS information for a simplistic structural system}

To illustrate the developed approach, the effect of structural system and DDS characteristics on the structural reliability and risk are quantified. For clarity, a simplistic structural system subjected to deterioration consisting of two components and a DDS comprising two sensors and a subspace based DDA (Figure 4). The structural system is described with its static, dynamic, deterioration, reliability and consequences characteristics as required and outlined in the previous sections.

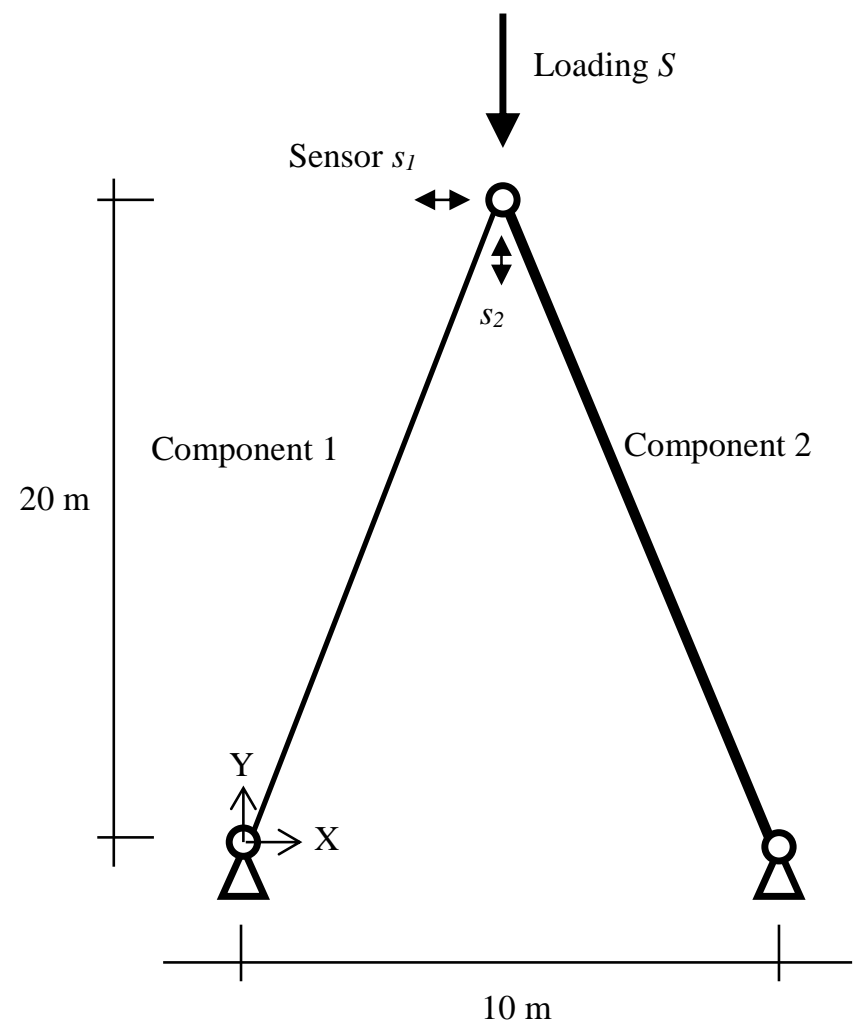

Figure 4: Structural system with sensor locations

The structural system properties are modelled with distributed component stiffness and mass subjected to a structural damping of $2 \%$ for each mode, see Table 1 . The system behaviour is calculated with the Finite Element method. For each of the structural components, $n_{D}=100$ damaged states $\psi_{1, j_{1}}$ and $\psi_{2, j_{2}}$ are considered, corresponding to stiffness loss from 0 to $10 \%$, respectively. The resulting system damage states are $\boldsymbol{\psi}_{\mathbf{j}}=\left\{\psi_{1, j_{1}}, \psi_{2, j_{2}}\right\}$ for $j_{1}, j_{2}=1, \ldots, n_{D}$.

Table 1 : Structural model properties

\begin{tabular}{lc} 
Parameter & Value \\
\hline Mass per component & 0.5 \\
\hline Stiffness of component 1: $E A_{1}$ & 1000 \\
\hline Stiffness of component 2: $E A_{2}$ & 2000 \\
\hline Damping ratio & $2 \%$ \\
\hline
\end{tabular}

Due to the absence of redundancy, the structural system reliability is modelled as a series system, yielding 
$P\left(F_{S}\right)=P\left(\bigcup_{i=1}^{n_{c}=2} M_{R, i} R_{i}\left(t_{S}\right)-M_{S} S_{i} \leq 0\right)$

The formulation contains the number of components $n_{c}=2$ with the random variables component resistance $R_{i}$ (dependent on the time $t_{S}$ ), system loading $S$ and their associated model uncertainties $M_{R, i}$ and $M_{S}$, respectively. The time dependent resistance $R_{i}\left(t_{S}\right)$ of the component $i$ is modelled with the initial resistance $R_{i, 0}$ and the time dependent damage $D_{i}\left(t_{S}\right)$, i.e.

$R_{i}(t)=R_{i, 0}\left(1-D_{i}\left(t_{S}\right)\right)$

For clarity, the temporal dependence of the damage is neglected in the further.

The structural reliability model is summarised in Table 2 and Table 3. The system loading is represented with a Weibull distributed random variable $S$ which results by equilibrium in the component loading $S_{i}$. The loading and resistance model uncertainties and the resistance model are determined according to [21] as Lognormal distributed with a standard deviation of $10 \%$. The component probability of failure is calibrated to $1 \cdot 10^{-3}$ (when not varied) by adjusting the mean of the component resistance in the undamaged state taking basis in ISO 2394 (2015) [49] and the JCSS Probabilistic Model Code [21]. The correlation of the resistances and the deterioration are modelled with a coefficient of correlation of 0.5 when not varied.

Table 2 : Structural reliability model

\begin{tabular}{|c|c|c|c|}
\hline Random variable & Distribution & Mean & Standard deviation \\
\hline Loading $S$ & WBL & 3.50 & 0.1 \\
\hline Model uncertainty $M_{S}$ & $\mathrm{LN}$ & 1.00 & 0.1 \\
\hline Component resistances in undamaged state $R_{0, i}$ & LN & Calibrated & 0.1 \\
\hline Model uncertainty $M_{R, i}$ & $\mathrm{LN}$ & 1.00 & 0.1 \\
\hline Damage $D_{i}$ & $\mathrm{~N}$ & 0.07 & 0.03 \\
\hline
\end{tabular}

Table 3 : Correlation model

\begin{tabular}{lc} 
Random variables & Coefficient of correlation \\
\hline \hline Resistances $\rho_{R_{0}}$ & 0.5 (when not varied) \\
\hline Damages $\rho_{D}$ & 0.5 (when not varied) \\
\hline
\end{tabular}

The consequence model for the calculation of risks builds upon generic normalized costs for component failure $C_{\mathrm{c}}=1.0$, structural system failure $C_{S}=100$ (see e.g. [2]) and the DDS, $C_{D D S}$, comprising the DDS 
investment $\left(1.33 \times 10^{-4}\right.$ per channel), installation $\left(1.33 \times 10^{-4}\right.$ per channel $)$ and operation $\left(1.33 \times 10^{-4}\right.$ per year $)$ in accordance with [39].

The DDS is modelled with the acceleration sensors $s_{1}$ in X-direction and $s_{2}$ in Y-direction recording the responses $y_{k}$ from system (3)-(5), using the subspace-based DDA as described in Section 2.2. Based on the dynamic structural system model, 1000 datasets of length $N=10000$ at a sampling frequency of $50 \mathrm{~Hz}$ are simulated for each of the undamaged and damaged states for both sensors from white noise excitation.

The probabilities of indication $P\left(I_{S} \mid \boldsymbol{\psi}_{\mathbf{j}}\right)$ and $P\left(I_{S} \mid \boldsymbol{\psi}_{0}\right)$ are determined for the considered DIV in (11) with the threshold $t_{D}$ corresponding to a 0.01 probability of a type I error (see also Figure 2 ). The DDA takes into account the uncertainties related to the measurement data of finite length $N$, which is due to the unknown ambient excitation and the measurement noise. Human errors in the application and operation are accounted by the multiplication of the PoI with a factor of 0.95, see [42].

The probabilities of indication based on data from sensor $s_{1}$ and based on data from sensor $s_{2}$ in dependency of the system damage state defined as axial stiffness reduction are depicted in Figure 5. It is observed that the probabilities of indication based on sensor $s_{2}$ are significantly higher which is caused by the higher axial stiffness of the system in Y-direction and thus higher absolute stiffness changes due to the simulated damages. It is further observed that a damage of similar size in both components can be detected with a higher probability than an individual damage in one of the components.
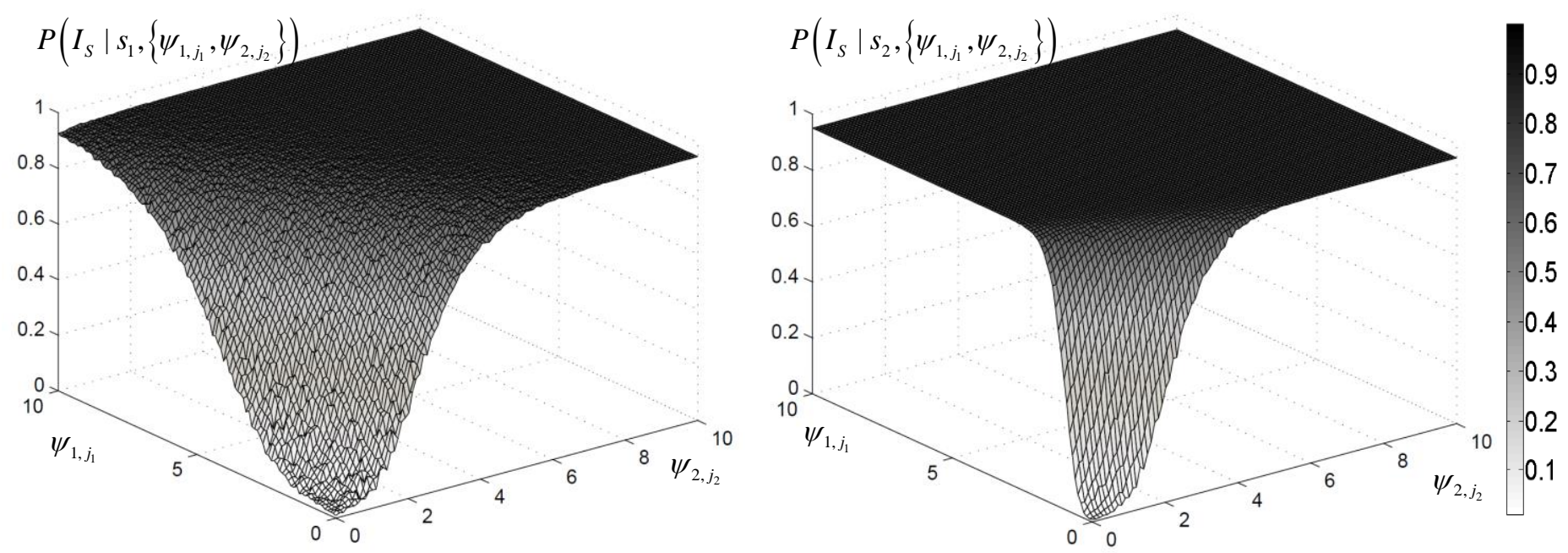

Figure 5: Probability of indication for sensor $s_{1}$ (left) and $s_{2}$ (right) in dependency of the system damage state

The DDS information are utilised to update the structural system reliability of the deteriorated structural system. The correlation characteristics of the deteriorated structural system may vary significantly due to the component, the system and deterioration characteristics (as identified in Section 2.1). The updated reliabilities and risks are thus depicted in dependency of the resistance and deterioration correlation to allow for more generality of the example.

The deteriorated series system without updating by DDS information shows a slight decrease of the structural system failure probability for both increasing the deterioration and the resistance correlation $\rho_{R_{0}}$ and 
$\rho_{D}$ (Figure 6). When utilizing the DDS information, the failure probability decreases and a higher decrease rate for the deterioration correlation is observed for sensor $s_{1}$ and $s_{2}$. However, both effects are significantly more pronounced for sensor $s_{2}$ due to the higher probabilities of indication (see Figure 6 left and right). The higher decrease rate for the damage correlation in comparison to the resistance correlation is explained by the higher probability of indication for correlated damages of the same size, i.e. the higher the system deterioration the better the DDS performance.

An exponential dependency of the structural system failure probability on the component probability of failure is observed (Figure 6 right). The dependency is explained by the interdependency of the component failure and the system failure. The system failure probability is more reduced when using sensor $s_{2}$ due to the higher probability of indication of the structural damages.
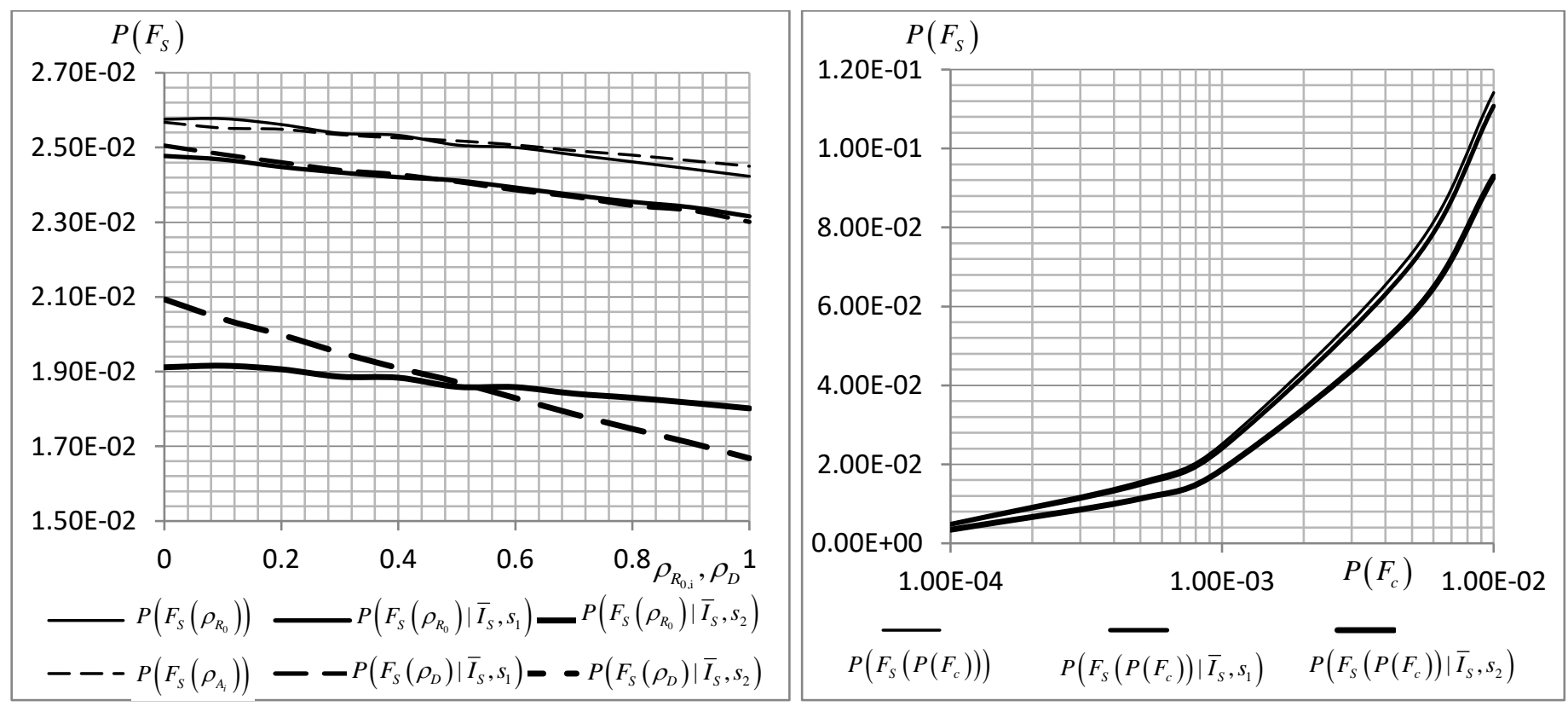

Figure 6: Prior and posterior system probability of failure $\left(P\left(F_{S}\right)\right.$ and $\left.P\left(F_{S} \mid \bar{I}_{S}\right)\right)$ in dependency of the resistance correlation, the damage correlation (left) and the probability of component failure (right) for different sensor positions.

The risk reduction $\Delta R$ and the relative risk reduction $\Delta R / R$ according to Equ. (21) and (22) in dependency of the damage and the resistance correlation are shown in Figure 7. The risk reduction for both sensors is positive despite considering the expected SHM costs which means that the expected SHM costs are overcompensated by the risk reduction due to the DDS information.

It is observed that sensor $s_{2}$ leads to a significantly higher risk reduction than sensor $s_{1}$ caused by higher reduction of the probability of system failure. The higher risk reduction decrease rate observed for the damage correlation is in line with the findings in [49].

The relative risk reduction relates the absolute risk reduction to the total risks not utilizing DDS information and can thus be seen as a measure for the significance of the risk reduction. The risk reduction varies between 2.3 and $6.0 \%$ for sensor $s_{1}$ and between 18.4 and $32.8 \%$ for sensor $s_{2}$ (Figure 7 right). The behaviour of the 
relative risk reduction in dependency of the damage and the resistance correlation is very similar to the risk reduction as the system failure probability varies linearly and to a limited extend.

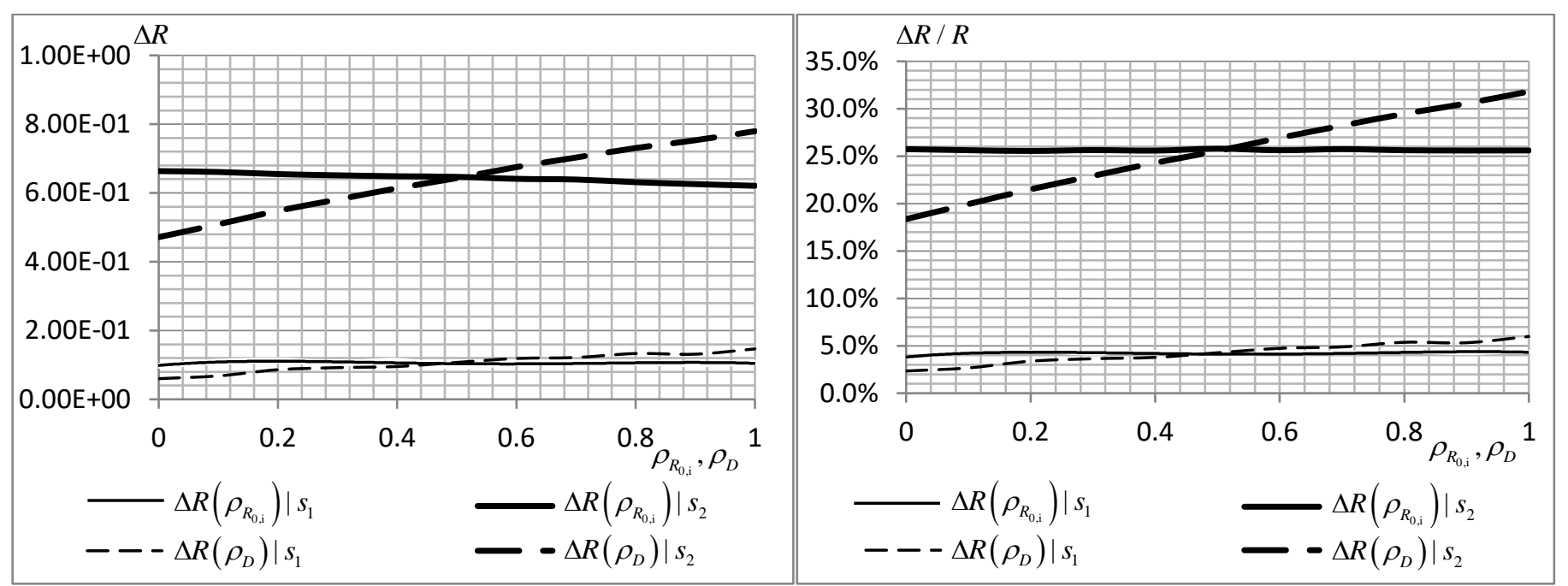

Figure 7: Structural risk reduction $\Delta R$ and $\Delta R / R$ in dependency of the resistance and the damage correlation for different sensor positions.

A higher absolute risk reduction is observed for systems with a higher probability of component and thus system failure (Figure 8 left). This effect was also observed for a ductile Daniels system with the SHM strategy of load monitoring [41]. However, the relative risk reduction (Figure 8 right) decreases as the system risk increase rate is higher than the risk reduction rate.

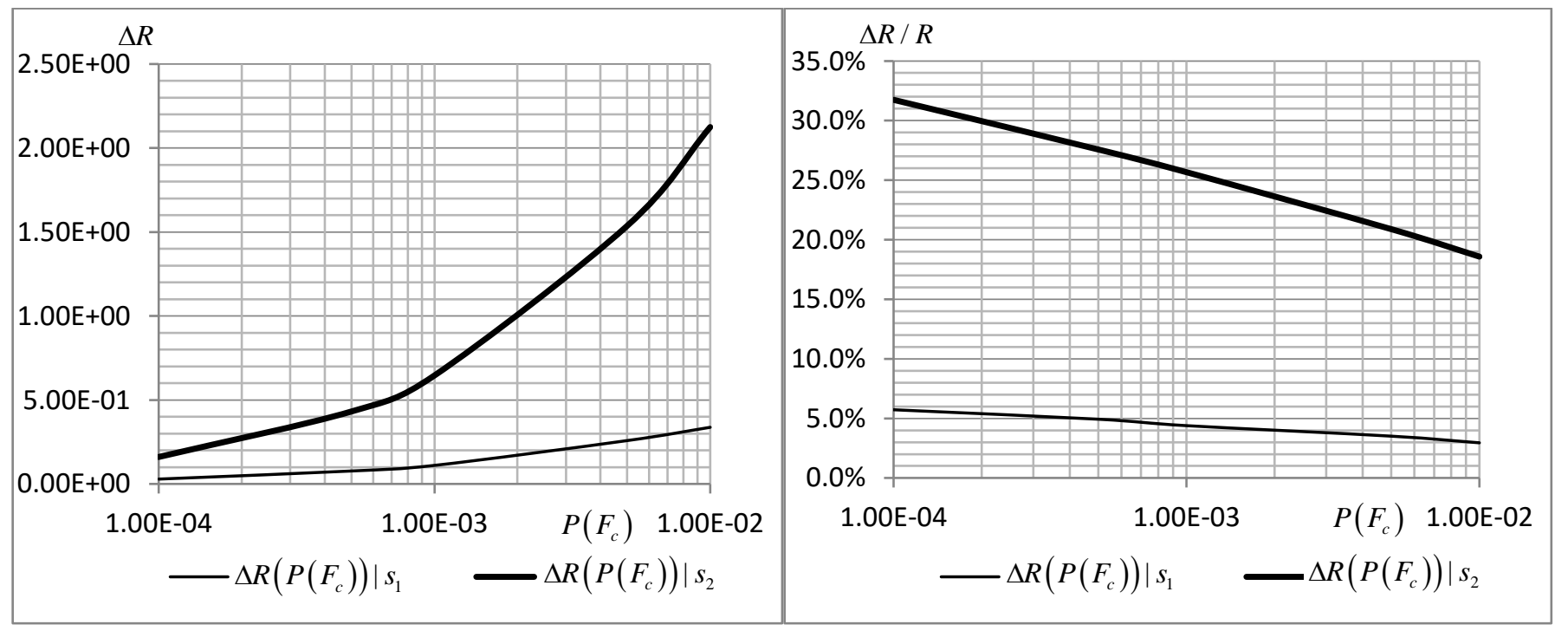

Figure 8: Structural risk reduction $\Delta R$ (left) and $\Delta R / R$ (right) in dependency of the component probability of failure for different sensor positions.

It has been demonstrated that a significantly higher uncertainty and risk reduction can be achieved with sensor $s_{2}$. The performance of the sensor in the context of this study relies on capturing more efficiently the dynamic behaviour of the structural system facilitating a higher sensitivity and thus a higher probability to detect small damages. For a further optimisation of DDS these characteristics and the interrelations of the structural and DD systems have to be considered. 


\section{UTILITY GAIN QUANTIFICATION FOR DAMAGE DETECTION INFORMATION}

The Value of Damage Detection Information, i.e. the utility gain by applying DDSs, can be quantified based on the approaches for the quantification of Value of Structural Health Monitoring Information ( $V$ ) [49], as the difference between the life cycle benefits $B_{1}$ and $B_{0}$ with and without the DDS strategy $i$ :

$V=B_{1}-B_{0}$

The expected value of the life cycle benefit $B_{0}$ is formulated as a prior decision analysis, i.e. the maximization of the expected benefits $b_{0}$ with the $k_{n}$ action choices $\mathbf{a}=\left[a_{1} \ldots a_{k} \ldots a_{k_{n}}\right]^{T}$ and the $l_{n}$ structural performance uncertainties $\mathbf{X}_{k}=\left[X_{1} \ldots X_{l} \ldots X_{l_{n}}\right]^{T}$ :

$B_{0}=E_{X_{k, l}}\left[b_{0}\left(a_{k}^{*, 0}, X_{l}\right)\right]$ with $a_{k}^{*, 0}=\underset{a_{k}}{\arg \max }\left(E_{X_{k, l}}\left[b_{0}\left(a_{k}, X_{l}\right)\right]\right)$.

Utilizing DDS strategies $s_{i}$, the expected value of the life cycle benefit $B_{1}$ is calculated by additionally considering the $j_{n}$ uncertain DDS information $\mathbf{I}_{s_{i}}=\left[I_{s_{i}, 1} \ldots I_{s_{i}, j} \ldots I_{s_{i}, j_{n}}\right]^{T}$ with the extensive form of a preposterior decision analysis:

$B_{1}=E_{Z_{s_{i}, j}}\left[E_{X_{k, l}}^{\prime \prime}\left[b_{i}\left(s_{i}^{*}, I_{s_{i}, j}, a_{k}^{*, i}, X_{l}\right)\right]\right]$

with $\left(s_{i}^{*}, a_{k}^{*, i}\right)=\underset{s_{i}}{\arg \max } E_{I_{s_{i}, j}}\left[\underset{a_{k}}{\arg \max } E_{X_{l}}^{\prime \prime}\left[b_{i}\left(s_{i}, I_{s_{i}, j}, a_{k}, X_{l}\right)\right]\right]$.

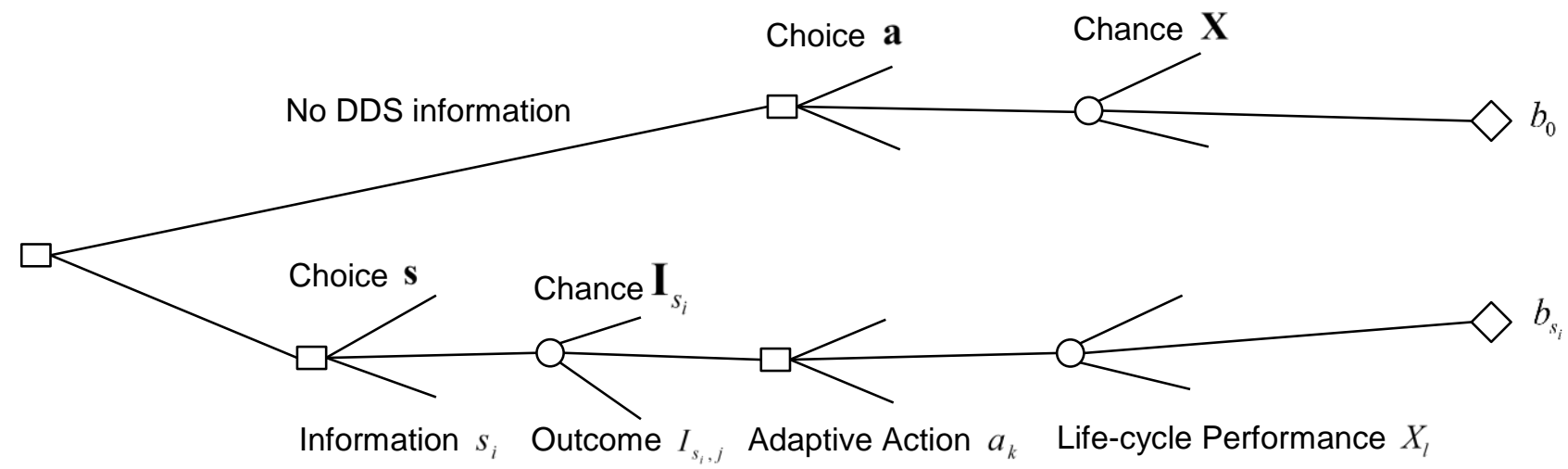

Figure 9: Illustration of a decision tree for the assessment of the Value of Information containing decision nodes (rectangulars) and chance nodes (circles)

The calculation of the expected benefits necessitates explicit benefit, cost and risk models in dependency DDS strategies, its outcomes, the actions and the life cycle performance. These models are exemplarily developed in the next section for a case study with a bridge girder system subjected to deterioration. 


\section{CASE STUDY: VALUE OF DAMAGE DETECTION INFORMATION FOR A PRATT TRUSS BRIDGE GIRDER}

A statically determinate Pratt truss bridge girder is analysed as shown in Figure 9. It is assumed that the Pratt truss bridge girder has been operated for 5 years without inspection. A further operation until the end of the service life $T_{S L}$ of 50 years is intended. There are indications that the bridge may undergo an abnormal and very high deterioration. The bridge manager knows that a DDS will deliver more information on the condition of the structure but does not know at which point in time during the service life the condition assessment should be performed. In order to determine an optimal point in time, the bridge manager performs a Value of DDS Information analysis.

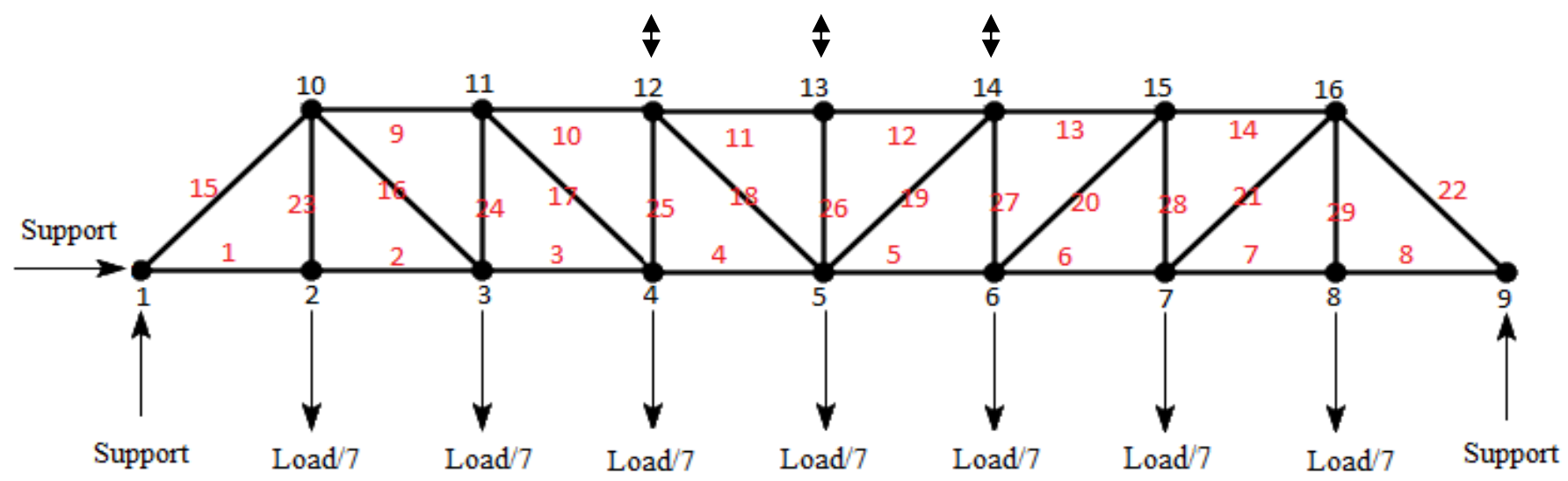

Figure 10: Pratt truss bridge girder with a distributed load (arrows) and the sensor locations (double arrows).

The bridge is assumed to be in two system states namely in the failure or safe state. Failure of the truss is caused by component failure due the non-redundant system characteristic and will lead to the costs $C_{F}$. Component failure is caused by extreme loads in combination with the damage development over time. The bridge manager has two options, i.e. to do nothing (action $a_{0}$ ) or to repair (action $a_{1}$ ) which will cost $C_{R}$. Repair is modelled here as a full reconditioning and it is assumed that all damaged components are exchanged.

The probability of system failure $P\left(F_{S}\right)$ can be calculated with a series system formulation with annual (year $j$ ) damage increments $\Delta_{D, i, j}$. The initial resistance is reduced by the square of the resistance reduction, which can be shown to be proportional to a corrosion induced diameter and consequently section loss. The section loss is also directly proportional to the stiffness loss for which the PoIs are determined.

$P\left(F_{S}\right)=P\left(\bigcup_{i=1}^{n_{c}=29} M_{R, i} R_{i, 0}\left(1-\sum_{j}^{t} \Delta_{D, j}\right)^{2}-M_{S} S_{i} \leq 0\right)$

The static, dynamic and the structural reliability models of the Pratt truss bridge girder are summarized in Table 2 and Table 4 . The annual deterioration has been assessed and $\Delta_{D, i, j}$ is assumed to follow a Lognormal distribution with a mean of 0.001 and a standard deviation of 0.001 . The mean of the resistance $R_{i, 0}$ is calibrated 
to a probability of $1 \cdot 10^{-6}$ disregarding any damage, considering that the consequence of failure is large and the relative costs of safety measures are small, [21] and [50]. The probabilistic annual extreme loading $S$ applied vertically on the truss and it is evenly distributed on the lower nodes $2,3,4,5,6,7,8$ with $S_{i}=1 / 7 \cdot S$

Table 4 : Structural model properties

\begin{tabular}{lr} 
Parameter & Value \\
\hline \hline Mass per component & 0.02 \\
\hline Young's modules $E$ & 14400 \\
\hline Cross section $A$ & $10 / 144$ \\
\hline Length of non-diagonal element & 10 \\
\hline Length of diagonal element & $10 \sqrt{2}$ \\
\hline Damping ratio & $2 \%$ \\
\hline
\end{tabular}

The cumulative probability of system failure with time and with changes of the damage and resistance correlation coefficient is shown in Figure 11. For a constant coefficient of correlation, the probability of system failure increases with time due to the accumulated deterioration damage. When varying the coefficient of correlation from $0.1,0.5$ to 0.9 , the results indicate that with an increase of the coefficient of correlation, the probability of system failure decreases.

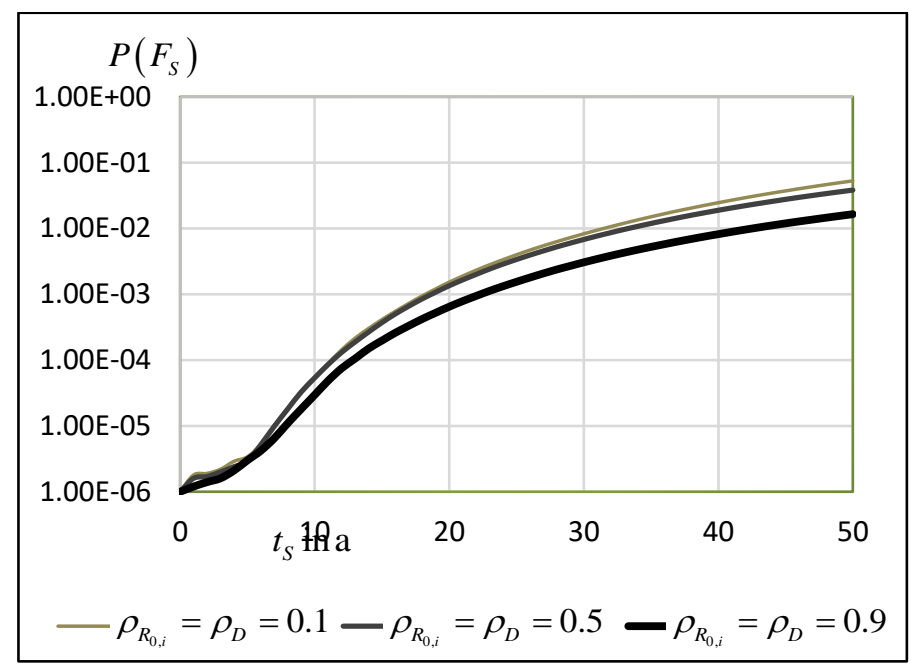

Figure 11: Probability of system failure with time with varied $\rho_{R_{0, i}}=\rho_{D}=0.1,0.5,0.9$.

The damage detection system is modelled with acceleration sensors located in node 12, 13, 14 of the truss in vertical direction recording the response using the subspace based DDA (Figure 10). The probabilities of indication and the probability of truss system failure given the DDS information of no-indication are calculated following Section 3.2. The individual probabilities and an exemplary joint probability of indication are shown in Figure 12. A DDS employment causes costs of $C_{D D S}$ and may cause also damage localisation costs $C_{l o c}$ in case a damage is indicated it is decided to perform a repair. 


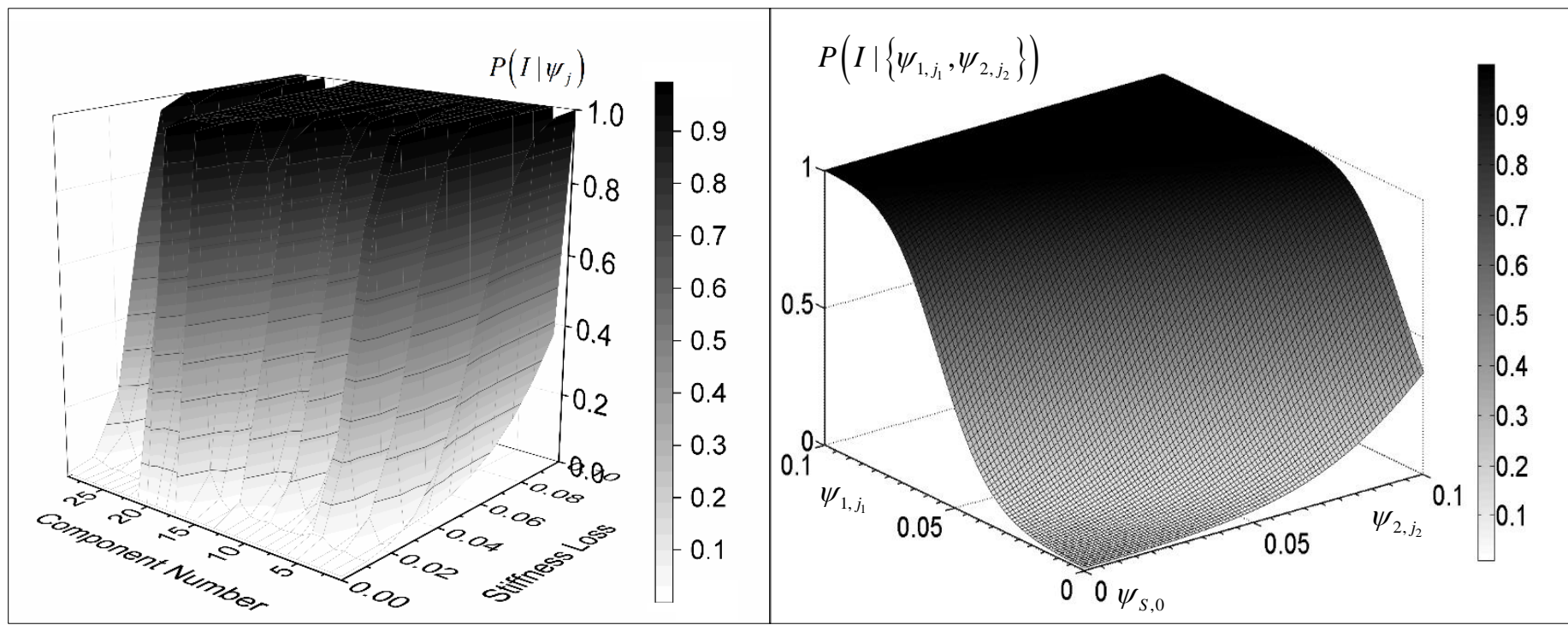

Figure 12: Probabilities of indication in dependency of the stiffness loss in 29 components (left) and joint probability of indication for components 1 and 2 (right).

In Figure 13, the effect of the updating of the structural system reliability is shown for one DDS utilisation (see Equ. (18)) for the different considered damage failure correlations and for different DDS employment years.

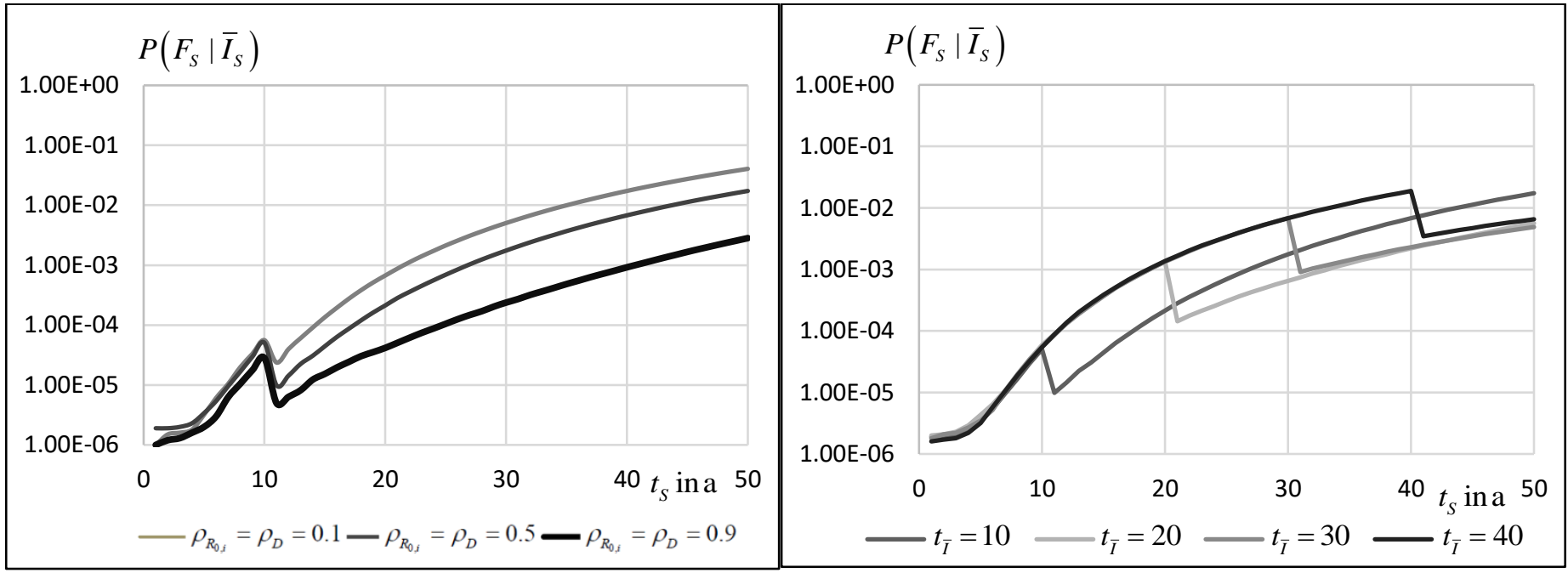

Figure 13: Posterior system probability of failure $P\left(F_{S} \mid \bar{I}_{S}\right)$ with varied $\rho_{R_{0, i}}=\rho_{\Delta_{D, i}}=0.1,0.5,0.9$ if implementing DDS at year 10 (left) and Posterior probability of system failure during service life when $\rho_{R_{0, i}}=\rho_{\Delta_{D, i}}=0.5$ if implementing DDS at year $10,20,30$ or 40 (right).

The illustration of the decision analysis for the quantification the Value of DDS Information $V$ is presented in Figure 14 taking basis in the formulation in Section 4. The analysis encompasses the basic decision whether to employ a DDS for condition assessment or not, the DSS strategies, their outcomes, the actions and the system service life performance as well as the associated consequences for each branch of the decision tree. 


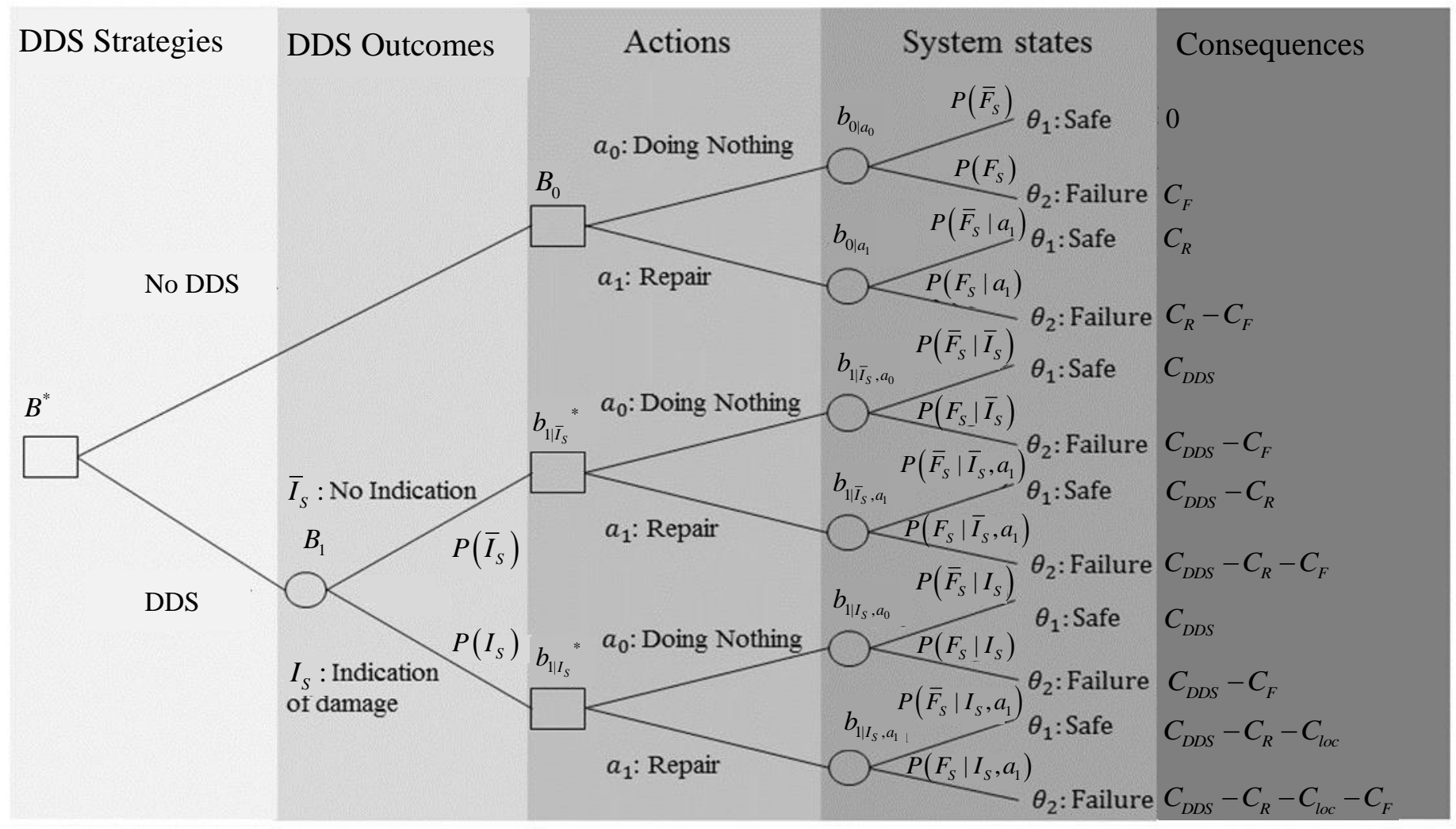

Figure 14: Illustration of decision tree combining a prior decision analysis (branch with no DDS) and a pre-posterior decision analysis to calculated the optimal expected life cycle benefit $B^{*}$ for one point in time.

The cost model based on [45] and [51] is shown in Table 5. All costs are discounted with a discount rate of 0.02. During the service life of the bridge, a target system failure probability of $1 \cdot 10^{-4}$ is required as the costs for safety measures are high and the consequences remain high, see [21] and [50]. The cost of repair $C_{R}$ increases with time due to the damage accumulation and is modelled in dependency of the investment costs $C_{I}$ and the service life $T_{S L}$, see Equ. (29). When the bridge is repaired, it is assumed that all damaged components are exchanged with new components.

$C_{R}=\frac{C_{I}}{T_{S L}+2-t}$

The failure costs $C_{F}$ are assumed to be a factor 100 higher than the investment costs due to indirect consequences. Localisation costs $C_{l o c}$ and DDS application costs $C_{D D S}$ are assumed to equal 0.1 following e.g. [45].

Table 5: Parameters in the cost and benefit analysis

\begin{tabular}{|c|c|c|c|c|c|}
\hline Variable & $\begin{array}{c}\text { Discount } \\
\text { rate } r\end{array}$ & $\begin{array}{c}\text { Investment } \\
\operatorname{cost} C_{I}\end{array}$ & $\begin{array}{c}\text { Failure } \\
\operatorname{cost} C_{F}\end{array}$ & $\begin{array}{c}\text { Localization } \\
\operatorname{cost} C_{l o c}\end{array}$ & $\begin{array}{c}\text { DDS } \\
\operatorname{cost} C_{D D S}\end{array}$ \\
\hline Value & 0.02 & 10 & 1000 & 0.1 & 0.1 \\
\hline
\end{tabular}

Figure 15 shows the expected costs and risks and the Value of DDS Information in dependency of the DDS employment year $t_{D D S}$. The Value of DDS Information is positive between year 7 and year 11 . The maximum 
is at year 7 with a significant relative Value of DDS Information of $11 \%$. Very low values of DDS Information are observed in year 6 where the DDS information do not influence the repair actions. Only DDS employment in year 7 will lead to changes in the repair actions and hence a reduction of the expected repair costs. The Value of DDS Information is decreasing in the consecutive years as the period for which the DDS information provide a risk reduction becomes shorter. A drop of the Value DDS Information occurs in year 13 as here the optimal action becomes repair also for the branch without the DDS information as enforced by the target reliability of $10^{-4}$.

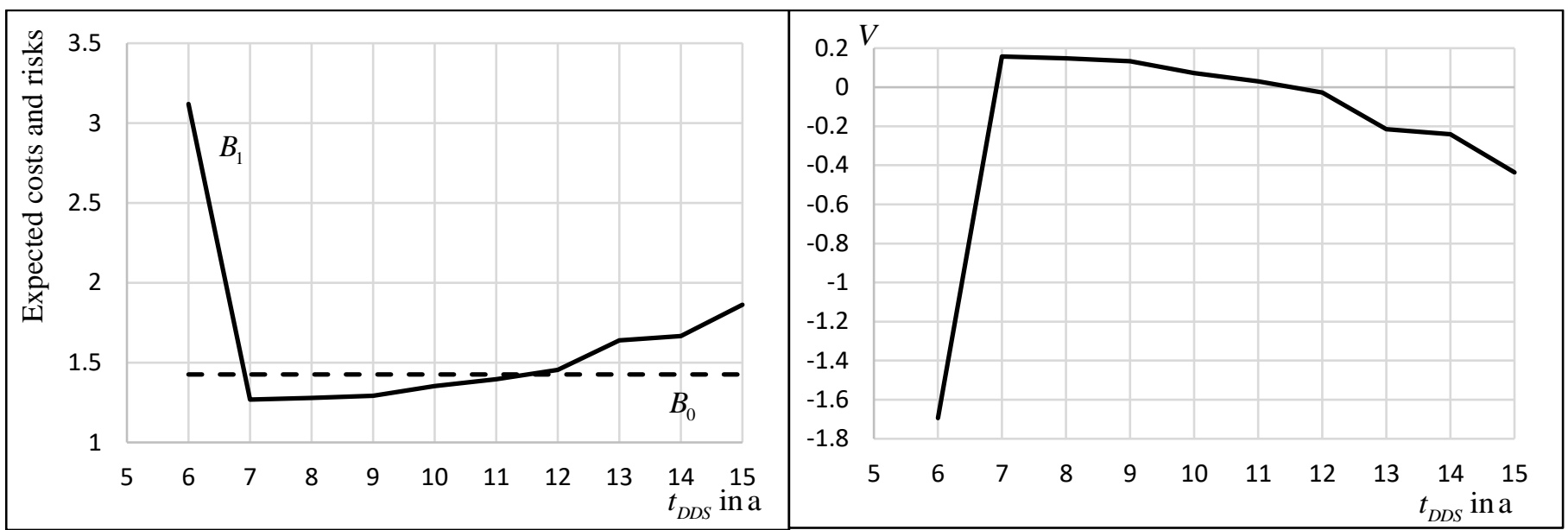

Figure 15: Expected costs and risks (left) and Value of DDS Information in dependency of the DDS employment year $t_{D D S}$ for $\rho_{R_{0, i}}=\rho_{\Delta_{D, i}}=0.9$ (right)

\section{CONCLUSIONS}

The introduced approach facilitates the updating of the structural reliability and risks with damage detection system (DDS) information on system level for both the DDS and the structural system. The DDS performance modelling accounts for the characteristics and dependencies of the structural system damage states and encompasses the measurement system (number of sensors, sensor positions, precision of the system including human errors) and the employed damage detection algorithms (DDAs). The structural system damage states necessitate a consistent modelling in terms of the static, dynamic and deterioration characteristics in order to derive the structural reliability and risk as well as the DDS performance models.

The introduced DDS performance modelling facilitates a comparison and assessment of various DDS, on the basis of the probabilistic indication characteristics on DDS and structural system level with e.g. the systemand/or component-wise and structural system specific probability of indication. The calculation of the DDS performance may be subjected to substantial demands either experimentally or computationally, as the system damage state space is increasing with the number of components in the exponent. Several strategies to overcome this challenge have been discussed and outlined. 
The quantification of the Value of DDS Information may serve as a basis for DDS design. In this perspective, a DDS (i.e. e.g. the number of sensors, the sensor positions, the precision, the DDA) can be optimised to achieve a maximum expected life cycle benefit for a specific structural system or a class of structural systems.

With two case studies, the potential of the approach has been demonstrated in terms of a significant Value of DDS Information and structural system risk reduction utilizing a subspace-based DDA. The approach is generalizable to other DDAs, requiring the indication characteristics for a discretization of the system damage state space for a chosen DDA.

\section{ACKNOWLEDGMENT}

The COST Action TU1402 on Quantifying the Value of Structural Health Monitoring is gratefully acknowledged for the inspiring discussions, contributions, and workshops across the scientific and engineering disciplines with researchers, industrial experts, and representatives of infrastructure operators, owners, and authorities.

\section{REFERENCES}

[1] Ayala-Uraga E, Moan T. System reliablity issues of offshore structures considering fatigue failure and updating based on inspection, in: 1st International ASRANet Colloquium, Glasgow, Scotland, 2002.

[2] Baker JW, Schubert M, Faber MH. On the assessment of robustness. Structural Safety, 2008, 30:253-267.

[3] Balmès E, Basseville M, Bourquin F, Mevel L, Nasser H, Treyssède F. Merging sensor data from multiple temperature scenarios for vibration monitoring of civil structures. Structural health monitoring, 2008, 7(2):129-142.

[4] Basseville M, Abdelghani M, Benveniste A. Subspace-based fault detection algorithms for vibration monitoring. Automatica, 2000, 36(1):101109.

[5] Basseville M, Mevel L, Goursat M. Statistical model-based damage detection and localization: subspace-based residuals and damage-to-noise sensitivity ratios. Journal of Sound and Vibration, 2004, 275(3):769-794.

[6] Bernal D. Kalman filter damage detection in the presence of changing process and measurement noise. Mechanical Systems and Signal Processing, 2013, 39(1):361-371.

[7] Carden EP, Fanning P. Vibration based condition monitoring: a review. Structural Health Monitoring, 2004, 3(4):355-377.

[8] Deraemaeker A, Reynders E, De Roeck G, Kullaa J. Vibration-based structural health monitoring using output-only measurements under changing environment. Mechanical Systems and Signal Processing, 2008, 22(1):34-56.

[9] Ditlevsen O, Madsen HO. Structural Reliability Methods, Coastal, Maritime and Structural Engineering and Department of Mechanical Engineering, Technical University of Denmark, 2005.

[10] Döhler M, Mevel L. Fast multi-order computation of system matrices in subspace-based system identification. Control Engineering Practice, 2012, 20(9):882-894.

[11] Döhler M, Mevel L. Subspace-based fault detection robust to changes in the noise covariances. Automatica, 2013, 49(9):2734-2743.

[12] Döhler M, Hille F, Mevel L, Rücker W. Structural health monitoring with statistical methods during progressive damage test of S101 Bridge. Engineering Structures, 2014, 69:183-193.

[13] Döhler M, Mevel L, Hille F. Subspace-based damage detection under changes in the ambient excitation statistics. Mechanical Systems and Signal Processing, 2014, 45(1):207-224.

[14] Faber MH, Straub D, Maes MA. A computational framework for risk assessment of RC structures using indicators. Computer-Aided Civil and Infrastructure Engineering, 2006, 21:216-230. 
[15] Farrar CR, Doebling SW, Nix DA. Vibration-based structural damage identification. Philosophical Transactions of the Royal Society of London A: Mathematical, Physical and Engineering Sciences, 2001, 359(1778): 131-149.

[16] Farrar CR, Worden K. An introduction to structural health monitoring. Philosophical Transactions of the Royal Society of London A: Mathematical, Physical and Engineering Sciences, 2007, 365(1851):303-315.

[17] Farrar CR, Worden K. Structural Health Monitoring: A Machine Learning Perspective, John Wiley \& Sons, Inc., 2013.

[18] Gandossi L, Annis C. Probability of Detection Curves: Statistical Best-Practices, European Commission, Joint Research Centre, Institute for Energy, 2010.

[19] Gollwitzer S, Rackwitz R. On the reliability of Daniels systems. Structural Safety, 1990, 7:229-243.

[20] Hong HP. Reliability analysis with nondestructive inspection. Structural Safety, 1997, 19:383-395.

[21] JCSS, Probabilistic Model Code, JCSS Joint Committee on Structural Safety, 2006.

[22] Lanata F, Schoefs F. Probabilistic assessment of the efficiency of algorithms for crack detection on instrumented RC beams: a non-model based method, in: EACS 2012 - 5th European Conference on Structural Control, Genova, Italy, 2012.

[23] Lee Y, Song J. System reliability updating of fatigue-induced sequential failures. Journal of Structural Engineering, 2013, 140:04013074.

[24] Madsen HO. Model updating in reliability theory, in: Proceedings of ICASP 5, Vancouver, Canada, 1987, pp. 564-577.

[25] Magalhaes F, Cunha A, Caetano E. Vibration based structural health monitoring of an arch bridge: from automated OMA to damage detection. Mechanical Systems and Signal Processing, 2012, 28:212-228.

[26] Moan T. Reliability and risk analysis for design and operations planning of offshore structures. Structural Safety \& Reliability, Rotterdam, 1994.

[27] Moan T, Song R. Implications of inspection updating on system fatigue reliability of offshore structures. Journal of Offshore Mechanics and Arctic Engineering, 2000, 122:173-180.

[28] Myers RH, Montgomery DC. Response Surface Methodology, 3rd Edition ed., John Wiley \& Sons, Inc., 2007.

[29] Nishijima K, Maes MA, Goyet J, Faber MH. Constrained optimization of component reliabilities in complex systems. Structural Safety, 2009, 31:168-178.

[30] Peeters B, De Roeck G. Reference-based stochastic subspace identification for output-only modal analysis. Mechanical Systems and Signal Processing, 1999, 13(6):855-878.

[31] Qin J, Faber MH. Risk management of large RC structures within spatial information system. Computer-Aided Civil and Infrastructure Engineering, 2012, 27:385-405.

[32] Schneider R, Fischer J, Bügler M, Thöns S, Borrmann A, Straub D. Assessing and updating the reliability of concrete bridges subjected to spatial deterioration - principles and software implementation. Structural Concrete, 2015, 16(3):356-365.

[33] Schoefs F, Clément A. Nouy A. Assessment of ROC curves for inspection of random fields. Structural Safety, 2009, 31:409-419.

[34] Singh R. Three Decades of NDI Reliability Assessment, 2000.

[35] Straub D. Generic Approaches to Risk Based Inspection Planning for Steel Structures. Chair of Risk and Safety, Institute of Structural Engineering, ETH Zürich, Zürich, 2004.

[36] Straub D. Reliability updating with inspection and monitoring data in deteriorating reinforced concrete slabs, in: 11th International Conference on Applications of Statistics and Probability in Civil Engineering (ICASP). Zurich. Switzerland., 2011.

[37] Straub D, Kiureghian AD. Reliability acceptance criteria for deteriorating elements of structural systems. Journal of Structural Engineering, 2011, 137(12), 1573-1582.

[38] Thöns S, Döhler M. Structural reliability updating with stochastic subspace damage detection information, in: EACS 2012 - 5th European Conference on Structural Control, Genoa, Italy, 2012.

[39] Thöns S, Faber MH, Rücker W. Optimal design of monitoring systems for risk reduction and operation benefits. SRESA's International Journal of Life Cycle Reliablity and Safety Engineering, 2014, 3:1-10.

[40] Thöns S, Lanata F. Risk and operation optimized damage detection and inspection systems, in: 11th International Conference on Structural Safety \& Reliability (ICOSSAR 2013), New York, USA, 2013.

[41] Thöns S, Schneider R, Faber MH. Quantification of the value of structural health monitoring information for fatigue deteriorating structural systems, in: 12th International Conference on Applications of Statistics and Probability in Civil Engineering (ICASP12), Vancouver, Canada, 2015.

[42] Wall M, Wedgwood FA, Burch S. Modelling of NDT reliability (POD) and applying corrections for human factors, NDT, 1998.

[43] Worden K, Manson G, Fieller NRJ. Damage detection using outlier analysis. Journal of Sound and Vibration, 2000, $229(3)$ : 647-667.

[44] Yang N. Application of reliability methods to fatigue, quality assurance and maintenance, in: G.I. Schuëller, M. Shinozuka, Yao (Eds.) Proceedings of the 6th International Conference of Structural Safety \& Reliability Balkema Rotterdam, 1994, pp. 3-18. 
[45] Qin, J., S. Thöns, and M.H. Faber, On the value of SHM in the context of service life integrity management, in 12th International Conference on Applications of Statistics and Probability in Civil Engineering, ICASP12. 2015: Vancouver, Canada.

[46] Long, L., S. Thöns, and M. Döhler, 'Damage Detection and Deteriorating Structural Systems', in Proceedings of the 2017 International Workshop on Structural Health Monitoring (IWSHM) (Stanford University, Stanford, CA USA: Accepted).

[47] Döhler, M. and S. Thöns (2016). Efficient Structural System Reliability Updating with Subspace-Based Damage Detection Information. European Workshop on Structural Health Monitoring (EWSHM), Bilbao, Spain, 5-8 July 2016.

[48] Papadimitriou, C. Beck, J.L. and Katafygiotis, L.S. (2001). Updating Robust Reliability Using Structural Test Data. Probabilistic Engineering Mechanics, 16(2), 103-113.

[49] Thöns S. On the Value of Monitoring Information for the Structural Integrity and Risk Management. Computer-Aided Civil and Infrastructure Engineering. 2018; 33:79-94.

[50] ISO 2394 (2015). General Principles on Reliability for Structures ISO 2394.

[51] Higuchi, S. (2007). Cost-Benefit Based Maintenance Optimization for Deteriorating Structures, Doctoral dissertation, Fakultät Bauingenieurwesen, Bauhaus-Universität Weimar, Germany

[52] Faber MH, editor. Risk Assessment in Engineering - Principles, System Representation \& Risk Criteria: JCSS Joint Committee on Structural Safety; 2008 